\title{
Variability of light transmission through Arctic land-fast sea ice during spring
}

\author{
M. Nicolaus ${ }^{1}$, C. Petrich ${ }^{2}$, S. R. Hudson ${ }^{3}$, and M. A. Granskog ${ }^{3}$ \\ ${ }^{1}$ Alfred-Wegener-Institut, Helmholtz-Zentrum für Polar- und Meeresforschung, Bremerhaven, Germany \\ ${ }^{2}$ Norut Narvik AS, Narvik, Norway \\ ${ }^{3}$ Norwegian Polar Institute, Fram Centre, Troms $\emptyset$, Norway \\ Correspondence to: M. Nicolaus (marcel.nicolaus@awi.de)
}

Received: 17 September 2012 - Published in The Cryosphere Discuss.: 12 October 2012

Revised: 16 May 2013 - Accepted: 17 May 2013 - Published: 20 June 2013

\begin{abstract}
The amount of solar radiation transmitted through Arctic sea ice is determined by the thickness and physical properties of snow and sea ice. Light transmittance is highly variable in space and time since thickness and physical properties of snow and sea ice are highly heterogeneous on variable time and length scales. We present field measurements of under-ice irradiance along transects under undeformed land-fast sea ice at Barrow, Alaska (March, May, and June 2010). The measurements were performed with a spectral radiometer mounted on a floating under-ice sled. The objective was to quantify the spatial variability of light transmittance through snow and sea ice, and to compare this variability along its seasonal evolution. Along with optical measurements, snow depth, sea ice thickness, and freeboard were recorded, and ice cores were analyzed for chlorophyll $a$ and particulate matter. Our results show that snow cover variability prior to onset of snow melt causes as much relative spatial variability of light transmittance as the contrast of ponded and white ice during summer. Both before and after melt onset, measured transmittances fell in a range from one third to three times the mean value. In addition, we found a twentyfold increase of light transmittance as a result of partial snowmelt, showing the seasonal evolution of transmittance through sea ice far exceeds the spatial variability. However, prior melt onset, light transmittance was time invariant and differences in under-ice irradiance were directly related to the spatial variability of the snow cover.
\end{abstract}

\section{Introduction}

Physical properties and the thickness of sea ice and snow cover play a key role for the Arctic climate and ecosystems. They control the amount of solar irradiance reflected to the atmosphere, absorbed within snow and sea ice, and transmitted into the ocean beneath sea ice. Hence, they determine the surface radiation budget of the Arctic Ocean, and also impact global radiative forcing (Hudson, 2011). The interaction of sunlight and sea ice (including its snow cover) has been investigated in manifold studies at different places and during different seasons in the Arctic. In particular, the role of surface optical properties has been investigated extensively from in situ observations (Grenfell and Perovich, 2004; Perovich et al., 1998, 2002b), numerical simulations (Gardner and Sharp, 2010; Grenfell, 1991; Light et al., 2003), laboratory experiments (Perovich and Grenfell, 1981), airborne measurements (Hanesiak et al., 2001; Perovich et al., 2002a), and remote sensing (Comiso and Kwok, 1996; Hall et al., 2004; Hall and Martinec, 1985; Tschudi et al., 2001). From these studies, wavelength-integrated (total or broadband) albedo is reasonably well quantified for different surface types, and the seasonal evolution is described in several ways for multi-year sea ice (Nicolaus et al., 2010a; Perovich et al., 2002a) and seasonal land-fast sea ice (Perovich and Polashenski, 2012; Perovich et al., 1998, 2012). Combining this seasonality with Arctic-wide datasets of sea-ice properties, Perovich et al. (2011) derived Arctic-wide estimates of energy fluxes into the sea ice (net solar short-wave irradiance). However, optical properties and in particular the surface albedo of first-year Arctic sea ice and melt ponds are 
still the subject of various studies, in particular with respect to its spatial and spectral variability. This is because most studies of the last decades have concentrated on land-fast or multi-year pack ice.

Compared to surface albedo, little is known about the spatial and temporal variability of the amount of solar irradiance under sea ice (Ehn et al., 2011; Gradinger et al., 2009; Hudson et al., 2013; Light et al., 2008; Nicolaus et al., 2010a; Perovich et al., 1998). One major challenge is accessibility of the under-ice environment, such that measurements are mostly limited to time-consuming spot measurements through bore holes. As a result, biologically and climatologically relevant energy budgets of specific regions and seasons cannot be given yet. A first comprehensive understanding of under-ice irradiance was achieved using data from SHEBA (Surface Heat Budget of the Arctic Ocean) and radiative transfer simulations (Light et al., 2008). The first successful, long-term observations of transmitted irradiance through Arctic sea ice by an autonomous station, part of the drift of Tara in 2007, show a seasonality inverse to that of surface albedo and highlight the importance of biological processes and their timing (Nicolaus et al., 2010a, b).

The first detailed studies of spatial variability of light transmission through sea ice were performed under land-fast sea ice off Barrow, Alaska, by Perovich et al. (1998) and Maykut and Grenfell (1975). Maykut and Grenfell (1975) performed their measurements in early June 1972. They highlight the role of surface properties for light transmittance, and demonstrate the general shapes of spectra of transmitted irradiance for seasonally-evolving surface conditions. Perovich et al. (1998) observed highly variable total transmittances between 0.0005 and 0.008 during April. This variability was mainly caused by differences in snow depth. Petrich et al. (2012b) showed through Monte Carlo simulations that light conditions at the bottom of sea ice are influenced by snow and sea-ice properties within a radius of 1 to 2 $\mathrm{m}$. They also highlight the importance of sea-ice texture in the bottommost decimeters on shaping the light field and light spreading under sea ice. Transmittance measurements through pond-covered sea ice, performed by divers, allowed to quantify light transmittance and the spreading of light under sea ice in order to describe the light environment under highly heterogeneous ponded and white ice during summer (Ehn et al., 2011; Hudson et al., 2013). The most comprehensive data set of spectral radiation data under melt-pond covered summer Arctic sea ice with a focus on spatial variability was presented by Nicolaus et al. (2012). Their analyses focused on the large-scale difference of first-year ice (FYI) and multi-year ice (MYI), showing that FYI transmits three times more light than MYI. This results from different optical properties, reduced sea-ice thickness (smaller freeboard), and higher surface coverage of melt ponds on FYI.

At the same time, connections between physical, biological, and optical properties of sea ice have long been recognized (Grenfell and Maykut, 1977; Maykut and Grenfell,
1975). Also more recent studies (Arrigo et al., 2012; Mundy et al., 2009) have highlighted the role of light for under-ice habitats and the timing of algal blooms under sea ice. The amount of sunlight transmitted though snow and sea ice into the upper ocean is of great importance for primary productivity and biogeochemical fluxes (Arrigo et al., 1991; Gradinger et al., 2009; Uusikivi et al., 2010), because it is the primary energy source for photosynthesis. Based on this, there is an ongoing discussion on how changing ice conditions and the increasing light availability under sea ice (Nicolaus et al., 2012) might alter primary productivity. Under-ice measurements of solar irradiance have also been used to calculate biomass at the bottom of sea ice as a non-destructive method (Mundy et al., 2007).

However, comparisons across transmittance studies is often hampered by the variability of snow, sea-ice, and weather conditions, and the need for combined studies of spatial variability and seasonal evolution arises. The goal of the present study is to quantify the spatial and seasonal variability of solar short-wave transmittance through Arctic sea ice. To accomplish this, we performed in-situ measurements of solar irradiance along horizontal transects under undeformed land-fast sea ice off Barrow, Alaska, in March, May, and June 2010. These measurements represent ice conditions before and after melt onset, but before melt ponds formed. Our analyses quantify spatial and temporal variability of light transmission, focusing on the range of photosynthetically active radiation (PAR, 400 to $700 \mathrm{~nm}$ ).

\section{Methods}

Measurements were performed on level, seasonal, land-fast sea ice at the site of the sea-ice observatory at Barrow, Alaska (Druckenmiller et al., 2009), on 22 March, 14 May, and 11 June 2010. The site was chosen for the availability of supplementary data from seasonally installed radiation and ice mass balance stations. These stations provided a local record of incident, reflected, and transmitted spectral irradiance (Nicolaus et al., 2010b), ice thickness, temperature, snow depth, and atmospheric data (Druckenmiller et al., 2009). Water depth was approximately $6 \mathrm{~m}$.

Incident and transmitted solar irradiance were measured simultaneously with two upward-looking Ramses spectral radiometers with advanced cosine collectors (Ramses ACC, Trios GmbH, Rastede, Germany). Sensors, data processing, and data quality are discussed in detail by Nicolaus et al. (2010b). One sensor was mounted on a buoyant sled and operated under the sea ice (under-ice irradiance, $E_{\mathrm{T}}$, with "T" for transmitted $\equiv E_{\mathrm{d}}$ (bottom, 400-700 nm)), and one sensor was mounted stationary as surface reference (incident solar irradiance, $E_{\mathrm{S}}$, with "S" for surface $\equiv E_{\mathrm{d}}$ (surface, 400-700 nm)) next to the access hole, approximately $1.5 \mathrm{~m}$ above the ice surface. Spectral and PAR transmittance, as well as mean values, were calculated as defined in Nicolaus 

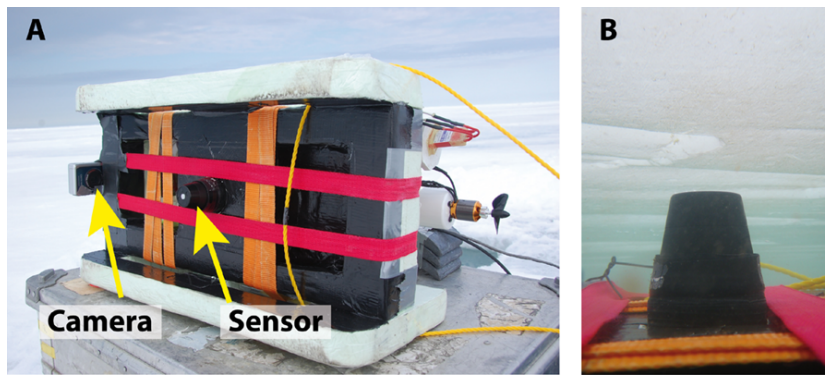

Fig. 1. (a) Sled lying on its side with radiometer in the center, a backward-looking on-board camera, and the yellow tether line at the back of the sled. The straps tie the propulsion to the sled (motor, speed controller and weights). (b) Photograph taken by the on-board camera during under-ice operations in June. The underside of the ice close to the sensor is white while ice in the distance appears to be cyan presumably because of preferential absorption of red light in water.

et al. (2010b). The distance between the radiometer on the sled and the ice bottom was $2 \pm 1 \mathrm{~cm}$, varying slightly with under-ice topography. Spectra were not corrected for absorption between the sensor and the ice bottom, because of the very small distance and the expected uncertainties related to such corrections (Nicolaus and Katlein, 2013). The under-ice radiometer was equipped with an additional inclination and pressure module (type SAMIP, Nicolaus et al., 2010b). From these pressure measurements, the depth of the radiometer and finally sea-ice draft was obtained for each spectrum.

The radiometer sled consisted of a buoyant frame with a centered hole for the radiometer, a means of propulsion that was controlled through a tether line, and an avalanche transmitter (Pieps DSP, Lebring, Austria; UHF transmitter as used in mountaineering to locate people buried by snow avalanches) for under-ice localization. Figure 1 shows the setup used in June. The sled was deployed through a rectangular access hole cut through the ice (Fig. 2). Prior to the measurements, the sled was propelled forward with electric motors until it became stuck or reached the end of the tether. Then the motors were turned off. Due to the simple construction, the sled was not able to move laterally or vertically. At the transect's end, the first radiation measurements were triggered synchronously for the under- and above-ice sensors. Afterwards, the horizontal position of the sled (and radiometer) was determined with an avalanche receiver by searching for it from the ice surface with least possible destruction of the snow and ice surface. Actual tether length and direction eased the search procedure. Then the sled was manually pulled toward the access hole at increments of nominally $0.5 \mathrm{~m}$. After each $0.5 \mathrm{~m}$ pull, both sensors were again triggered. The along-transect coordinate is the nominal path distance of the radiometer from the access hole. During transect measurements, the horizontal position of the under-ice radiometer was determined with an avalanche receiver (accuracy approximately $0.2 \mathrm{~m}$ ) every 5 to $10 \mathrm{~m}$. These tie points
Table 1. Vertically integrated sea-ice properties from all full-length cores obtained during the measurements in 2010. Missing values were not measured. Full profile data are available online (http://dx. doi.org/10.1594/PANGAEA.780223).

\begin{tabular}{llrrrr}
\hline Date & Core & $\begin{array}{r}\text { Core length } \\
(\mathrm{m})\end{array}$ & Salinity & $\begin{array}{r}\text { Chlorophyll } a \\
\left(\mathrm{mg} \mathrm{m}^{-2}\right)\end{array}$ & $\begin{array}{r}\text { Particulate matter } \\
\left(\mathrm{g} \mathrm{m}^{-2}\right)\end{array}$ \\
\hline $19 \mathrm{Mar}$ & $\mathrm{A}$ & 1.29 & 7.7 & 0.85 & \\
& $\mathrm{~B}$ & 1.29 & 6.6 & & 12.55 \\
$20 \mathrm{Mar}$ & $\mathrm{A}$ & 1.32 & 7.6 & 0.33 & \\
& $\mathrm{~B}$ & 1.30 & 7.7 & & 9.76 \\
& $\mathrm{C}$ & 1.26 & 7.3 & & 10.59 \\
& $\mathrm{D}$ & 1.25 & 6.3 & 0.39 & \\
\hline 13 May & $\mathrm{C}$ & 1.53 & 8.3 & 2.29 & 23.94 \\
$14 \mathrm{May}$ & $\mathrm{A}$ & 1.41 & 7.2 & 0.54 & 5.52 \\
& $\mathrm{~B}$ & 1.53 & 7.5 & 3.00 & 4.46 \\
\hline 11 June & $\mathrm{A}$ & 1.55 & 5.6 & 2.11 & 6.52 \\
& $\mathrm{~B}$ & 1.45 & 6.0 & 3.82 & 15.87 \\
\hline
\end{tabular}

were marked at the snow surface. After all measurements were completed, the exact distances from the marks to the access hole were measured with a tape measure. Measurements were performed around solar noon, and it took approximately $1.5 \mathrm{~h}$ to complete the transect.

On 22 March, the access hole was located in the middle of the transect (Figs. 2a, 3a). Starting from this hole, two transects, one $36 \mathrm{~m}$ and one $32 \mathrm{~m}$ long, were measured under clear-sky conditions. The transects headed in different directions from the access hole. Transect length was limited by under-ice topography that could not be passed since the sled had no means of vertical navigation. These two profiles were combined into one transect, consisting of 117 coincident measurements of incident and transmitted spectra. On 14 May, the access hole was at one end of an $80 \mathrm{~m}$ long transect (123 measurements, Figs. 2b, 3b) and the measurements were performed under overcast conditions with thin clouds. This transect length was limited by the cable length. On 11 June, two $20 \mathrm{~m}$-long transects were measured in similar directions from the access hole (Figs. 2c, 3c), because a strong current forced the sled in one particular direction. Transect lengths were again limited by under-ice topography. These two sub-profiles were combined into one transect, consisting of 71 paired spectral measurements. Cloud conditions were variable with changing fractions of clouds obstructing the solar disk. A compact camera was attached to the sled in June and programmed to take one photograph every $10 \mathrm{~s}$. Flash was disabled and an indicator light on the camera was covered to prevent interference with optical measurements. The ice underside, the radiometer and parts of the sled were in the field of view; the camera was oriented toward the access hole (Fig. 1b).

After completing the radiation measurements, ice thickness and freeboard were measured through $5 \mathrm{~cm}$-diameter auger holes spaced $5 \mathrm{~m}$ along each transect. Additional snow depth measurements were performed along the transect every 0.2 to $1.0 \mathrm{~m}$. The transects were located within $100 \mathrm{~m}$ 

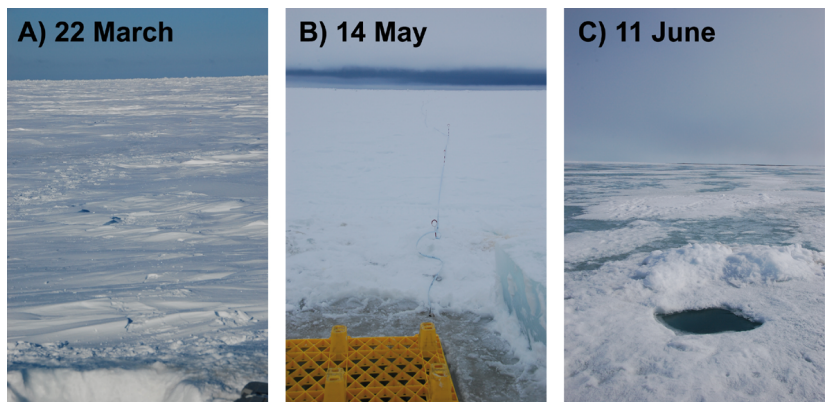

Fig. 2. Photographs of surface conditions along profiles in (a) March, (b) May, and (c) June 2010. All photographs were taken after completion of the measurements, which were performed under undisturbed surfaces. The snow pile next to the hole in June resulted from the hole construction. This part was removed for analyses.

of the site of the observatory and within $50 \mathrm{~m}$ of each other, on uniform ice. Since data sets have different spatial resolutions, snow and ice data were interpolated to derive a total ice thickness and snow depth at the locations of the spectral measurements. Observations that were obviously influenced by the access hole (within 2 to $5 \mathrm{~m}$ ) were not included.

After each transect, a number of sea-ice cores were retrieved along the profiles for salinity, chlorophyll $a(\mathrm{Chl} a)$, and particulate measurements (Table 1). In March, six cores were taken within a few meters of the access hole. In May and June three and two cores were taken along the transects, respectively. All optical, thickness, and ice-core data are available online from the Pangaea data publishing system under http://dx.doi.org/10.1594/PANGAEA.780223.

\section{Results and discussion}

\subsection{Thickness and melt of snow and sea ice}

In March, the mean and standard deviation of sea-ice thickness was $1.28 \pm 0.06 \mathrm{~m}$, snow depth was $0.22 \pm 0.08 \mathrm{~m}$, and freeboard was mostly positive (Figs. 3, 4). By May, seaice thickness increased to $1.47 \pm 0.06 \mathrm{~m}$ and snow depth increased to $0.27 \pm 0.06 \mathrm{~m}$, while modal snow depth remained unchanged at $0.25 \mathrm{~m}$. Regular visits and measurements of surface albedo show that surface melt started after 5 June, with the first melt ponds forming on 09 June (Polashenski et al., 2012), causing a reduction in mean snow depth to $0.07 \pm 0.03 \mathrm{~m}$ by the June measurements. Sea-ice thickness increased slightly to $1.50 \pm 0.02 \mathrm{~m}$. Freeboard was positive along the entire profile. The histograms in Fig. 4 illustrate that the range of sea-ice thickness and snow depth along the transects was largest in March and smallest in June. Changes in snow depth and snow properties can be seen in the photographs of surface conditions in Fig. 2, showing a visibly lower albedo and wet snow in June. These changes are ex-
Table 2. Incident solar radiation fluxes above $\left(E_{\mathrm{S}, \mathrm{PAR}}\right)$ and under $\left(E_{\mathrm{T}, \mathrm{PAR}}\right)$ sea ice, as well as transmittance $\left(T_{\mathrm{PAR}}\right)$ of photosynthetic active radiation (PAR).

\begin{tabular}{llrrr}
\hline & & 22 Mar & 14 May & 11 Jun \\
\cline { 3 - 5 }$n$ & Number of measurements & 117 & 123 & 71 \\
\hline \multirow{2}{*}{$E_{\mathrm{S}, \text { PAR }}$} & Mean $\left(\mathrm{W} \mathrm{m}^{-2}\right)$ & 153.1 & 262.4 & 229.8 \\
& Std $\left(\mathrm{W} \mathrm{m}^{-2}\right)$ & 8.0 & 33.4 & 30.7 \\
& Min $\left(\mathrm{W} \mathrm{m}^{-2}\right)$ & 141.1 & 214.3 & 194.8 \\
& Max $\left(\mathrm{W} \mathrm{m}^{-2}\right)$ & 161.1 & 327.8 & 332.7 \\
\hline \multirow{2}{*}{$E_{\mathrm{T}, \text { PAR }}$} & Mean $\left(\mathrm{W} \mathrm{m}^{-2}\right)$ & 0.34 & 0.49 & 9.40 \\
& Std $\left(\mathrm{W} \mathrm{m}^{-2}\right)$ & 0.36 & 0.17 & 4.28 \\
& Min $\left(\mathrm{W} \mathrm{m}^{-2}\right)$ & 0.06 & 0.16 & 3.87 \\
& Max $\left(\mathrm{W} \mathrm{m}^{-2}\right)$ & 1.80 & 0.94 & 17.50 \\
\hline \multirow{2}{*}{$T_{\mathrm{PAR}}$} & Mean & 0.0022 & 0.0019 & 0.041 \\
& Std & 0.0022 & 0.0006 & 0.019 \\
& Min & 0.0004 & 0.0006 & 0.014 \\
& Max & 0.0113 & 0.0035 & 0.086 \\
\hline
\end{tabular}

pected to strongly influence the optical measurements under the sea ice, presented below.

\subsection{Sea-ice properties}

Sea-ice salinity profiles measured during the March campaign showed C-shaped profiles typical of seasonal ice during the growth season, with the highest salinity of about 12 in the uppermost $0.05 \mathrm{~m}$ and a mean salinity of 7.2 (Table 1). In May, salinity profiles were very similar to the ones measured in March, containing just slightly more salt (mean 7.7). This indicates little if any flushing of sea ice until after our May transect. However, by 11 June the mean salinity decreased to 5.8 , indicative of flushing. Physical inspection of the ice underside in June showed a thinner and less pronounced layer of brittle sea-ice lamellae (not fully consolidated ice crystals) than in March and May, with less biota visible than in May but more than in March. Vertically integrated Chl $a$ content of the sea ice increased from $0.5 \mathrm{mg} \mathrm{m}^{-2}$ in March to over $2.0 \mathrm{mg} \mathrm{m}^{-2}$ in May and $3.0 \mathrm{mg} \mathrm{m}^{-2}$ in June. Maximum Chl $a$ concentrations as high as $35 \mathrm{mg} \mathrm{m}^{-3}$ were found in the bottommost $0.05 \mathrm{~m}$ in June. These concentrations are much lower than those found by Gradinger et al. (2009) at the same place during 2002. Also they are more than one order of magnitude lower than those used by Mundy et al. (2007) for their parameterization of optical properties and biomass estimates, based on springtime observations in Resolute Passage, Canada. The amount of particulate matter in the ice cores remained constant at $11 \mathrm{mg} \mathrm{m}^{-2}$. The highest particulate concentrations were always found in the uppermost $0.2 \mathrm{~m}$ of sea ice. Particulate concentrations in the snow were not measured. 

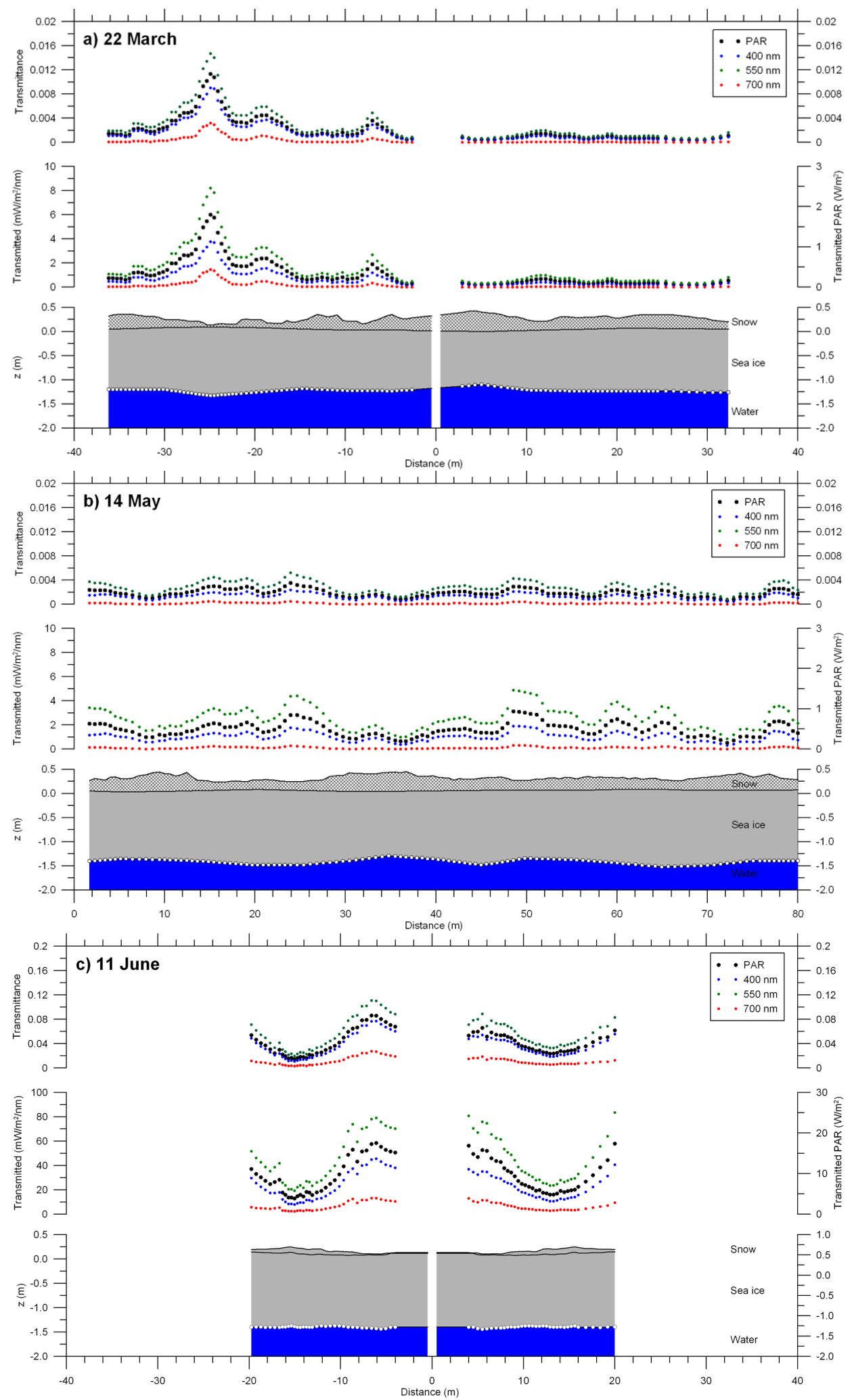

Fig. 3. Transect geometry (bottom), transmitted irradiance (middle), and transmittance (top) of snow and sea ice for each of the three transects in (a) March, (b) May, and (c) June 2010. Radiation data are given for photosynthetically active radiation (PAR, black circles) and spectral values at $400 \mathrm{~nm}$ (blue dots), $550 \mathrm{~nm}$ (green dots), and $700 \mathrm{~nm}$ (red dots). Note different scales (factor 10) on radiation data in June. $x=0$ denotes the center of the access hole of the sled. 

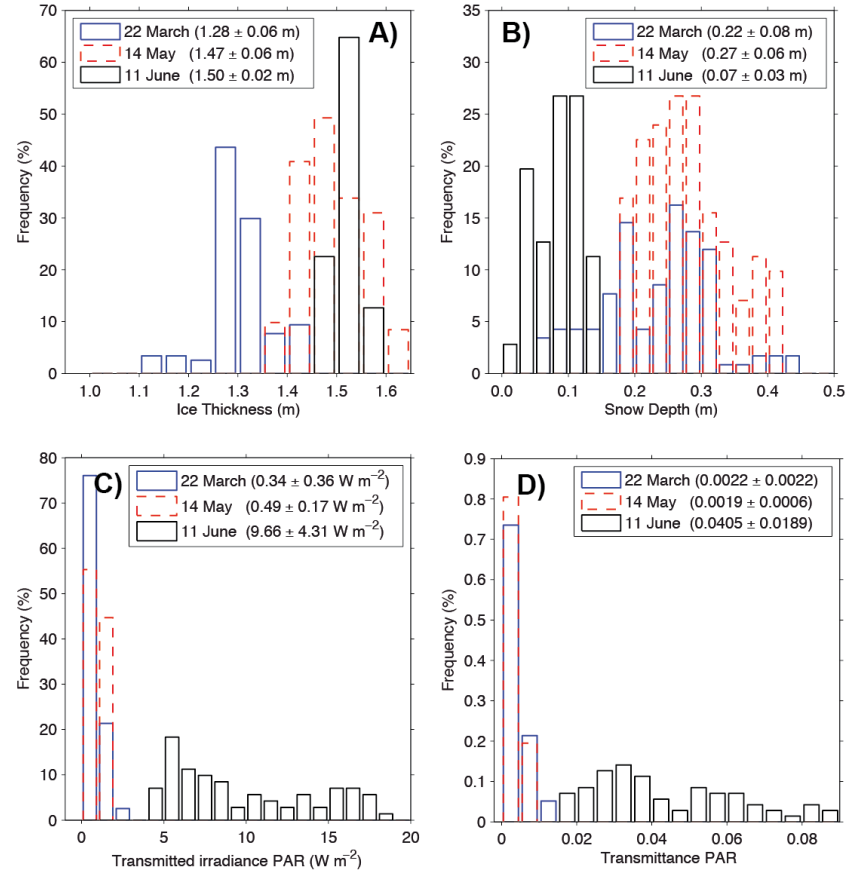

Fig. 4. Frequency distributions of (a) sea-ice thickness and (b) snow depth (c) transmitted irradiance of PAR, and (d) transmittance of PAR along the transects. Mean values of all distributions are given as mean \pm one standard deviation in the legends.

\subsection{Solar irradiance above and below sea ice}

Incident PAR irradiance at the surface, $E_{\mathrm{S}, \mathrm{PAR}}$, varied between the three campaigns. Due to differences in sky conditions, $E_{\mathrm{S}, \text { PAR }}$ was higher in May than in June. Also the

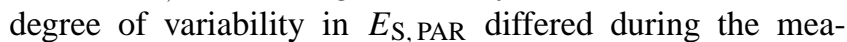
surements; $E_{\mathrm{S}, \mathrm{PAR}}$ varied only slightly $\left(153 \pm 8 \mathrm{~W} \mathrm{~m}^{-2}\right.$, $705 \mu \mathrm{E} \mathrm{s}^{-1} \mathrm{~m}^{-2}, \pm$ denotes one standard deviation) in March under clear sky conditions, while $E_{\mathrm{S} \text {, PAR }}$ was more variable in May $\left(262 \pm 33 \mathrm{~W} \mathrm{~m}^{-2}, 1207 \mu \mathrm{E} \mathrm{s}^{-1} \mathrm{~m}^{-2}\right)$ and June $\left(230 \pm 31 \mathrm{~W} \mathrm{~m}^{-2}, 1059 \mu \mathrm{Es}^{-1} \mathrm{~m}^{-2}\right)$, when the skies were overcast with changing cloud cover (Table 2). Transmitted solar irradiance recorded under sea ice, $E_{\mathrm{T}}$, varied significantly along each transect (spatial variability) and between the three transects (temporal evolution). Figure 3 shows the results of the under-ice measurements and illustrates the observed variability along each transect for three selected wavelengths in the PAR range $(400,550$, and $700 \mathrm{~nm})$ and for the total transmitted PAR $E_{\mathrm{T}, \text { PAR }}$. This variability was very pronounced in March, when the first profile (negative $\mathrm{x}$ values) had a range of $E_{\mathrm{T}, \text { PAR }}$ up to $1.8 \mathrm{~W} \mathrm{~m}^{-2}\left(8.3 \mu \mathrm{E} \mathrm{s}^{-1} \mathrm{~m}^{-2}\right)$ while the second profile had very little variability with all fluxes below $0.5 \mathrm{~W} \mathrm{~m}^{-2}\left(2.3 \mu \mathrm{E} \mathrm{s}^{-1} \mathrm{~m}^{-2}\right)$. The largest fluxes

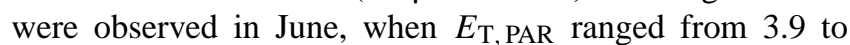
$17.5 \mathrm{~W} \mathrm{~m}^{-2}$ (18.0 to $81 \mu \mathrm{E} \mathrm{s}^{-1} \mathrm{~m}^{-2}$ ) (Table 2).

Comparing the three measurement dates, $E_{\mathrm{T}, \mathrm{PAR}}$ increased from $0.34 \pm 0.36 \mathrm{~W} \mathrm{~m}^{-2}\left(1.8 \mu \mathrm{E} \mathrm{s}^{-1} \mathrm{~m}^{-2}\right)$ in March
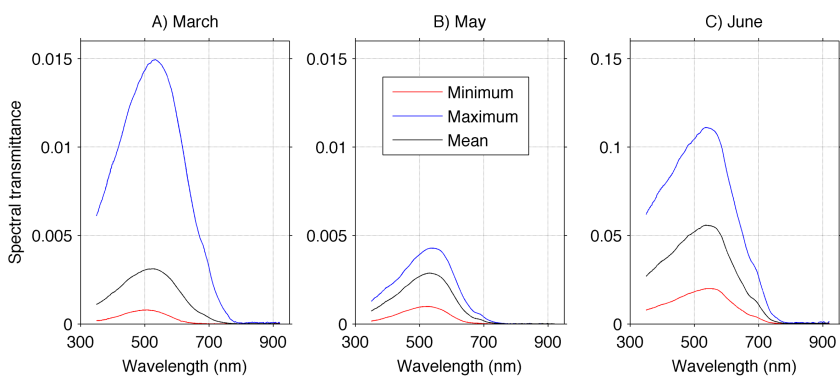

Fig. 5. Spectral transmittance through snow and sea ice in (a) March, (b) May, and (c) June 2010. For each transect the spectra for minimum and maximum light conditions as well as the mean spectrum for the transect are given. Note different scales (factor 10) for the data in June.

to $0.49 \pm 0.17 \mathrm{~W} \mathrm{~m}^{-2}\left(2.5 \mu \mathrm{E} \mathrm{s}^{-1} \mathrm{~m}^{-2}\right)$ in May, and to $9.40 \pm 4.28 \mathrm{~W} \mathrm{~m}^{-2}\left(50 \mu \mathrm{E} \mathrm{s}^{-1} \mathrm{~m}^{-2}\right)$ in June (Fig. 4). Most significant here is the increase by a factor of 20 from March and May to June. This increase in absolute fluxes was mostly related to changing snow conditions and was not primarily a consequence of higher sun elevation in June. Overcast con-

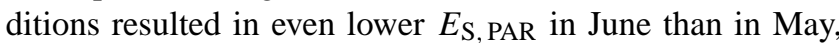
while under-ice fluxes were highest in June (Table 2). This observation also represents the transition from before to after melt onset conditions. While these fluxes quantify light transmission through sea ice along the profiles, it is difficult to distinguish between an increase of $E_{\mathrm{T}}$ due to the seasonal increase of $E_{\mathrm{S}}$ and the effect of seasonal changes in optical properties of snow and sea ice along the transects. Hence, we will concentrate on changes in mean transmittance of PAR, $T_{\mathrm{PAR}}=E_{\mathrm{T}, \mathrm{PAR}} / E_{\mathrm{S}, \mathrm{PAR}}$, in this manuscript, in order to assess the spatial variability and seasonal evolution in more detail.

\subsection{Spectral and PAR transmittance}

Figure 5 shows transmittance spectra for each transect, including the lowest and highest on each transect and the mean (average over all spectra along the transect). Data quality was good, even for the lowest light conditions. As expected, all spectra show a smooth distribution of energy up to a wavelength of $750 \mathrm{~nm}$. Beyond this, the ice is almost opaque. The wavelength of maximum transmittance increased slightly, from $523 \mathrm{~nm}$ in March, to $532 \mathrm{~nm}$ in May, and $536 \mathrm{~nm}$ in June, which would be consistent with an increase in colored dissolved organic matter (CDOM) (Granskog, 2012; Xu et al., 2012) although no indication for strong absorption peaks of Chl $a$ can be found. For comparison, the seasonal study by Nicolaus et al. (2010a) in the transpolar drift showed the wavelength of maximum transmittance remained consistently near $500 \mathrm{~nm}$ until the surface got water saturated. The shape of the transmittance spectra at Barrow changed only slightly, becoming a little wider with more transmittance in shorter wavelengths, after melt onset. These changes 
were similar to those observed in the transpolar drift in 2007 (Nicolaus et al., 2010a) for the same time of the year.

Mean transmittances of PAR, $T_{\mathrm{PAR}}$, were very similar in March (0.0022) and May (0.0019) (Fig. 4d), although the March value is strongly influenced by a section with thin snow and particularly high transmittance (Figs. 3a, 4b, 4d). Maximum values of $T_{\mathrm{PAR}}$ were 3 times higher in March than in May due to this region with thinner snow, but minimum and modal values are similar (Fig. 5a, b). The mode of $T_{\mathrm{PAR}}$ (lowest bin, Fig. 4d) remained the same (within the given resolution of 0.01 ), combining the effects of a moderate decrease in modal snow thickness, from 0.28 to $0.24 \mathrm{~m}$, and a slight increase in modal sea-ice thickness, by $0.19 \mathrm{~m}$. Comparing $T_{\mathrm{PAR}}$ before and after melt onset (but before meltpond formation along the transect), the values in March and May were over one order of magnitude lower than in June. In contrast to the small modal changes in $T_{\mathrm{PAR}}$ from March to May, every observed $T_{\mathrm{PAR}}$ in June (0.014 to 0.086 ) was larger than the maximum in March or May (Fig. 4d). Qualitatively, the same results hold for all wavelengths (Fig. 5). This increase occurred despite an increase of $0.22 \mathrm{~m}(17 \%)$ in seaice thickness from March to June, as this small increase in ice thickness was more than offset by a $0.15 \mathrm{~m}(67 \%)$ decrease in snow depth, illustrating the dominating role of snow in determining transmittance at this time of the year. Extinction coefficients for PAR are not presented here, as it is not possible to distinguish the different effects of snow and sea ice in this study.

\subsection{Spatial vs. seasonal variability}

Based on the three transects at three different dates over the course of the season, it was - to our knowledge for the first time - possible to compare the spatial and temporal variability of light transmittance through sea ice. It may be concluded that (1) prior to melt onset (i.e., March and May), the spatial variability (comparing minimum, mean, and maximum of $T_{\mathrm{PAR}}$ ) did not change significantly with time and (2) the relative spatial variability was constant even through the transition into the melt season. The ratio of $T_{\mathrm{PAR}} \mathrm{min}-$ $\mathrm{ima} /$ maxima and mean $T_{\mathrm{PAR}}$ was about 5 in March, 2 to 3 in May and 2 in June. Hence relative variability was approximately the same before and after melt onset, i.e., ranging from about one third to three times the mean value. In addition, the seasonal increase of transmittance of one order of magnitude in response to melt onset (from March/May to June) was much larger than the relative spatial variability along the transects.

Our observed variability in transmittance through spring snow and sea ice off Barrow, Alaska, matches well the results of Perovich et al. (1998) for the same region and season (April, before melt onset), which showed a variability between 0.0005 and 0.007 in transmittance along a 125 m-long transect. These ranges represent the uncertainty that should be expected for a single spot measurement of under-ice ra- diation (e.g., Gradinger et al., 2009; Light et al., 2008) or stationary setups (Nicolaus et al., 2010a). Variability continues to evolve further into the melt season, when enhanced melting results in distinct areas of melt ponds and white ice. Observations by Ehn et al. (2011) show PAR transmittances of 0.05 to 0.16 for snow free white ice and 0.38 to 0.67 for melt ponds for first-year ice in the Canadian Arctic. While Hudson et al. (2013) report for thin Arctic firstyear sea ice transmittances (broadband) of 0.11 and 0.39 for bare ice and melt ponds, respectively. These numbers indicate similar variability as observed here, indicating that premelt snow cover variations may cause as much relative spatial variability as the contrast of ponded and bare ice with surface scattering layer (white ice) summer sea ice. Nicolaus et al. (2012) found a larger variability at the end of the melt season, when a bi-modal distribution of transmittances was found, with peaks for ponded and white ice. Modal transmittance through ponds was 5 (MYI) to 14 (FYI) times higher than through white ice. In addition, a wide range of transmittance variability was observed (but not quantified) within the white ice and ponded ice. However, the data set as a whole is difficult to compare, since it comprises a much boarder range of snow and ice conditions than in this study.

For a detailed comparison of under-ice irradiance with snow depth, the horizontal spreading of light in sea ice has to be considered. This spread results in a 1 to $2 \mathrm{~m}$ footprint of the measurement, depending on ice-cover properties and solar zenith and azimuth angles (Ehn et al., 2011; Petrich et al., $2012 b)$. Since this is less than the spatial correlation length of snow features (e.g., Petrich et al., 2012a; Sturm et al., 2002), optical measurements can be interpreted based on locally averaged snow depths in addition to ice thickness and ice type observations.

Comparing the spatial variability with the 20 -fold seasonal increase of transmittances from March to June (prior to meltpond formation), it may be concluded that inter-seasonal variability is much larger than spatial variability when the melt season is included in considerations. For comparison, during the transpolar drift of Tara in 2007 (Nicolaus et al., 2010a), transmittance of PAR increased from 0.003 before melt onset, to 0.056 after melt onset when the surface was almost entirely ponded. This also represents a 20 -fold increase of PAR transmittance over the course of seasons, but on MYI and without consideration of spatial variability.

Our observations show for the first time the temporal evolution of the spatial variability of transmittance through sea ice. In particular, no systematic changes in relative variability were found once a snow cover had formed (i.e., March and May) through onset of snow melt (i.e., June). This may bear implications for large-scale modeling as "transmittance seasons" may be defined, with each season having its own mean transmittance, but with all having the same relative variability. This study confirms the importance of the role of snow for radiation transfer through snow and sea ice, as e.g., described by Warren (1982) and Perovich (1998). The effect of 
snow is a nearly wavelength-independent reduction of visible and near-UV transmittance, wavelengths at which absorption is low in pure ice and extinction is dominated by scattering, which is nearly wavelength independent (Warren et al., 2006). At longer wavelengths, where the absorption coefficient of ice increases, the significance of snow depth is reduced on thick ice since light will be absorbed by sea ice.

\subsection{Biomass estimates}

In order to estimate sea-ice biomass from the optical measurements, the method of normalized difference indices (NDIs) was applied, as suggested by Mundy et al. (2007) based on data from Resolute Passage. Correlating these indices with snow depths, it was possible to show the independence of the method from snow depth and snow properties (data not shown). However, calculated biomass estimates from the spectral measurements exceeded measurements by an order of magnitude. Mean concentrations along the transects would be $43.1 \pm 7.8 \mathrm{mg} \mathrm{m}^{-2}$ for March, $45.7 \pm 7.3 \mathrm{mg} \mathrm{m}^{-2}$ for May, and $63.7 \pm 2.6 \mathrm{mg} \mathrm{m}^{-2}$ for June (compared to the measurements summarized in Table 1). It is assumed that the main reasons for this are (1) Chl $a$ concentrations in this study $\left(<3 \mathrm{mg} \mathrm{m}^{-2}\right)$ were too low to allow the application of the algorithm from Resolute Passage (up to $110 \mathrm{mg} \mathrm{m}^{-2}$ ), (2) the high load of particulate matter (up to $24 \mathrm{~g} \mathrm{~m}^{-2}$ ) in this study can affect spectral transmittance, (3) biological processes that change the pigment composition, e.g., regional differences in algal communities, and (4) nonlinear aggregate effects exist at high abundances (possibly present in the data used by Mundy et al., 2007). It was also not possible to derive our own index based on the few icecores collected, or to use established methods from oceanoptics applications in the open ocean, since these include wavelengths around $670 \mathrm{~nm}$, which are strongly influenced by the snow cover (Perovich et al., 1993). Hence it is necessary to perform comprehensive sampling of ice cores and optical data, in order to develop improved methods to derive biomass estimates from under-ice irradiance measurements for a wider variety of ice types. Finally, these results suggest that it might be necessary to develop such methods individually for different ice types and locations, e.g., influenced by differences in particulate matter load.

\section{Conclusions}

Repeated transects of under-ice radiation measurements on land-fast sea ice allowed a quantification of seasonal and spatial variability of light conditions under sea ice. The measurements allow a unique comparison of seasonal and spatial variability and highlight the significance of spatial variability for energy transfer and habitat conditions. Invariance was observed that led us to propose the existence of "transmittance seasons". Each season would allow for simplified numerical treatment, which could be exploited in large-scale analyses of the under-ice light climate. In particular, it was found that (1) prior to onset of melt (i.e., March and May), the spatial variability did not change with time, (2) the relative spatial variability was constant even during the transition into the melt season, and (3) the seasonal increase in transmittance from before melt onset to advanced snow melt is much larger than relative spatial variability in either period.

Variability in transmittance was dominated by the variability in snow depth and snow optical properties. Despite similar incident irradiances (at the observation times), the underice irradiances increased by a factor of twenty between May and June, due to the increase in transmittance alone. Longer days and, at times, higher incident fluxes further enhance this increase in energy availability beneath the ice. All this variability is of paramount importance for biological productivity and ice decay. Nevertheless, more comprehensive under-ice radiation measurements are needed for a more generalized and large-scale understanding of the under-ice energy budget for physical, biological, and geochemical applications.

The under-ice sled approach used here is new and has good potential for similar, and extended, applications. Data on spatial variability are still sparse, while point measurements provide limited information, without having many installations operating seasonally. While even greater possibilities arise from the use of remotely operated vehicles (ROVs), as realized by Nicolaus et al. (2012), under-ice sleds reduce cost, size, demands on operator skills, and logistics requirements. Gathering much larger data sets through the use of ROVs or AUVs (autonomous underwater vehicles) will allow to apply more geo-statistical analyses. However, studies by Petrich et al. (2012a) of similar ice conditions and Sturm et al. (2002) on comprehensive snow transects, suggest that transects in the order of hundreds of meters are necessary to obtain statistically robust results.

Acknowledgements. This project was based on the initiative and support of Sebastian Gerland (Norwegian Polar Institute, Troms $\varnothing$ ) and Hajo Eicken (University of Alaska Fairbanks, UAF). We are most grateful for the exceptional support of field measurements by Dirk Kalmbach and Polona Itkin (both Alfred-Wegener-Institut, Helmholtz-Zentrum für Polar- und Meeresforschung, Bremerhaven, Germany, AWI), and Joshua Jones (UAF). Jennifer Peussner and Christian Katlein (both AWI) helped with the analysis of spectral data. Mette Kaufmann (UAF) kindly performed laboratory analyses of field samples. Data acquisition of the sea ice observatory at Barrow was funded under National Science Foundation grant OPP-0856867 (SIZONET). Martin Vancoppenolle and one anonymous reviewer as well as the editor Jean-Louis Tison helped with their constructive comments to improve the manuscript. Manuscript preparation was supported by the Norwegian Research Council (NFR) through a German-Norwegian exchange program (grant 199844). Additional funding was received from the NFR grants 196143/S30, 197236/V30, 195153, and 193592 (AMORA).

Edited by: J.-L. Tison 


\section{References}

Arrigo, K. R., Sullivan, C. W., and Kremer, J. K.: A Bio-optical Model of Antarctic Sea Ice, J. Geophys. Res., 96, 10581-10592, 1991.

Arrigo, K. R., Perovich, D. K., Pickart, R. S., Brown, Z. W., van Dijken, G. L., Lowry, K. E., Mills, M. M., Palmer, M. A., Balch, W. M., Bahr, F., Bates, N. R., Benitez-Nelson, C., Bowler, B., Brownlee, E., Ehn, J. K., Frey, K. E., Garley, R., Laney, S. R., Lubelczyk, L., Mathis, J., Matsuoka, A., Mitchell, B. G., Moore, G. W. K., Ortega-Retuerta, E., Pal, S., Polashenski, C. M., Reynolds, R. A., Schieber, B., Sosik, H. M., Stephens, M., and Swift, J. H.: Massive Phytoplankton Blooms Under Arctic Sea Ice, Science, 336, 6087, 1408-1408, doi:10.1126/science.1215065, 2012.

Comiso, J. C. and Kwok, R.: Surface and radiative characteristics of the summer Arctic sea ice cover from multisensor satellite observations, J. Geophys. Res., 101, C12, doi:10.1029/96JC02816, 1996.

Druckenmiller, M. L., Eicken, H., Johnson, M. A., Pringle, D. J., and Williams, C. C.: Toward an integrated coastal sea-ice observatory: System components and a case study at Barrow, Alaska, Cold Reg. Sci. Technol., 56, 61-72, doi:10.1016/j.coldregions.2008.12.003, 2009.

Ehn, J. K., Mundy, C. J., Barber, D. G., Hop, H., Rossnagel, A., and Stewart, J.: Impact of horizontal spreading on light propagation in melt pond covered seasonal sea ice in the Canadian Arctic, J. Geophys. Res.-Oc., 116, C00G02, doi:10.1029/2010jc006908, 2011

Gardner, A. S. and Sharp, M.: A review of snow and ice albedo and the development of a new physically based broadband albedo parameterization, J. Geophys. Res., 115, F01009, doi:10.1029/2009JF001444, 2010

Gradinger, R. R., Kaufman, M. R., and Bluhm, B. A.: Pivotal role of sea ice sediments in the seasonal development of nearshore Arctic fast ice biota, Mar. Ecol.-Prog. Ser., 394, 49-63, doi:10.3354/meps08320, 2009.

Granskog, M.: Changes in spectral slopes of colored dissolved organic matter absorption with mixing and removal in a terrestrially dominated marine system (Hudson Bay, Canada), Mar. Chem., 134, 13510-13519, doi:10.1016/j.marchem.2012.02.008, 2012.

Grenfell, T. C.: A Radiative Transfer Model for Sea Ice With Vertical Structure Variations, J. Geophys. Res., 96, 16991-17001, 1991.

Grenfell, T. C. and Maykut, G. A.: The optical properties of ice and snow in the Arctic basin, J. Glaciol., 18, 445-463, 1977.

Grenfell, T. C. and Perovich, D. K.: Seasonal and spatial evolution of albedo in a snow-ice-land-ocean environment, J. Geophys. Res., 109, C01001, doi:10.1029/2003JC001866, 2004.

Hall, D. K. and Martinec, J.: Remote sensing of ice and snow, Chapman and Hall, London, 189 pp., 1985.

Hall, D. K., Key, J. R., Casey, K. A., Riggs, G. A., and Cavalieri, D. J.: Sea Ice Surface Temperature Product from MODIS, IEEE Trans. Geosci. Remote Sens., 42, 1076-1087, 2004.

Hanesiak, J. M., Barber, D. G., De Abreu, R. A., and Yackel, J. J.: Local and regional albedo observations of arctic first-year sea ice during melt ponding, J. Geophys. Res., 106, 1005-1016, 2001.

Hudson, S. R.: Estimating the global radiative impact of the sea icealbedo feedback in the Arctic, J. Geophys. Res.-Atmospheres,
116, D16102, doi:10.1029/2011jd015804, 2011.

Hudson, S. R., Granskog, M. A., Sundfjord, A., Randelhoff, A., Renner, A. H. H., and Divine, D. V.: Energy budget of first-year Arctic sea ice in advanced stages of melt, Geophys. Res. Lett., 40, doi:10.1002/grl.50517, 2013.

Light, B., Maykut, G. A., and Grenfell, T. C.: A two-dimensional Monte Carlo model of radiative transfer in sea ice, J. Geophys. Res.-Oceans, 108, C7, doi:10.1029/2002jc001513, 2003.

Light, B., Grenfell, T. C., and Perovich, D. K.: Transmission and absorption of solar radiation by Arctic sea ice during the melt season, J. Geophys. Res., 113, C03023, doi:10.1029/2006JC003977, 2008.

Maykut, G. A. and Grenfell, T. C.: Spectral distribution of light beneath 1st-year sea ice in Arctic Ocean, Limnol.Oceanogr., 20, 554-563, 1975.

Mundy, C. J., Ehn, J. K., Barber, D. G., and Michel, C.: Influence of snow cover and algae on the spectral dependence of transmitted irradiance through Arctic landfast first-year sea ice, J. Geophys. Res., 112, C03007, doi:10.1029/2006JC003683, 2007.

Mundy, C. J., Gosselin, M., Ehn, J., Gratton, Y., Rossnagel, A., Barber, D. G., Martin, J., Tremblay, J. E., Palmer, M., Arrigo, K. R., Darnis, G., Fortier, L., Else, B., and Papakyriakou, T.: Contribution of under-ice primary production to an ice-edge upwelling phytoplankton bloom in the Canadian Beaufort Sea, Geophys. Res. Lett., 36, L17601, doi:10.1029/2009g1038837, 2009.

Nicolaus, M. and Katlein, C.: Mapping radiation transfer through sea ice using a remotely operated vehicle (ROV), The Cryosphere, 71-15, doi:10.5194/tc-7-1-2013, 2013.

Nicolaus, M., Gerland, S., Hudson, S. R., Hanson, S., Haapala, J., and Perovich, D. K.: Seasonality of spectral albedo and transmissivity as observed in the Arctic Transpolar Drift in 2007, J. Geophys. Res., 115, C11011, doi:10.1029/2009JC006074, 2010a.

Nicolaus, M., Hudson, S. R., Gerland, S., and Munderloh, K.: A modern concept for autonomous and continuous measurements of spectral albedo and transmittance of sea ice, Cold Reg. Sci. Technol., 62, 14-28, doi:10.1016/j.coldregions.2010.03.001, 2010b.

Nicolaus, M., Katlein, C., Maslanik, J., and Hendricks, S.: Changes in Arctic sea ice result in increasing light transmittance and absorption, Geophys. Res. Lett., 39, 24, L24501, doi:10.1029/2012GL053738, 2012.

Perovich, D. and Grenfell, T. C.: Laboratory studies of the optical properties of young sea ice, J. Glaciol., 27, 331-346, 1981.

Perovich, D. K., Cota, G. F., Maykut, G. A., and Grenfell, T. C.: Bio-optical Observations of First-Year Arctic Sea Ice, Geophys. Res. Lett., 20, 11, 1059-1062, 1993.

Perovich, D. K., Roesler, C. S., and Pegau, W. S.: Variability in Arctic sea ice optical properties, J. Geophys. Res.-Oceans, 103, 1193-1208, 1998.

Perovich, D. K., Grenfell, T. C., Light, B., and Hobbs, P. V.: Seasonal evolution of the albedo of multiyear Arctic sea ice, J. Geophys. Res., 107, C10, doi:10.1029/2000JC000438, 2002a.

Perovich, D. K., Tucker, W. B., and Ligett, K. A.: Aerial observations of the evolution of ice surface conditions during summer, $\mathrm{J}$. Geophys. Res., 107, C10, doi:10.1029/2000JC000449, 2002 b.

Perovich, D. K., Jones, K. F., Light, B., Eicken, H., Markus, T., Stroeve, J., and Lindsay, R.: Solar partitioning in a changing Arctic sea-ice cover, Ann. Glaciol., 52, 192-196, 2011. 
Perovich, D. K. and Polashenski, C.: Albedo evolution of seasonal Arctic sea ice, Geophys. Res. Lett., 39, L08501, doi:10.1029/2012GL051432, 2012.

Petrich, C., Eicken, H., Polashenski, C. M., Sturm, M., Harbeck, J. P., Perovich, D. K., and Finnegan, D. C.: Snow dunes: A controlling factor of melt pond distribution on Arctic sea ice, J. Geophys. Res.-Oceans, 117, C09029, doi:10.1029/2012jc008192, 2012a.

Petrich, C., Nicolaus, M., and Gradinger, R.: Sensitivity of the light field under sea ice to spatially inhomogeneous optical properties and incident light assessed with three-dimensional Monte Carlo radiative transfer simulations, Cold Reg. Sci. Technol., 7, 31-11, doi:10.1016/j.coldregions.2011.12.004, 2012b.

Polashenski, C., Perovich, D., and Courville, Z.: The mechanisms of sea ice melt pond formation and evolution, J. Geophys. Res.Oceans, 117, C01001, doi:10.1029/2011jc007231, 2012.

Sturm, M., Holmgren, J., and Perovich, D. K.: Winter snow cover on the sea ice of the Arctic Ocean at the Surface Heat Budget of the Arctic Ocean (SHEBA): Temporal evolution and spatial variablility, J. Geophys. Res., 107, C10, doi:10.1029/2000JC000400, 2002.
Tschudi, M. A., Curry, J. A., and Maslanik, J. A.: Airborne observations of summertime surface features and their effect on surface albedo during FIRE/SHEBA, J. Geophys. Res., 106, 1533515344, 2001.

Uusikivi, J., Vähätalo, A. V., Granskog, M. A., and Sommaruga, R.: Contribution of mycosporine-like amino acids and colored dissolved and particulate matter to sea ice optical properties and ultraviolet attenuation, Limnol. Oceanogr., 55, 703-713, 2010.

Warren, S. G.: Optical properties of snow, Rev. Geophys. Space Phys., 20, 67-89, 1982.

Warren, S. G., Brandt, R. E., and Grenfell, T. C.: Visible and near-ultraviolet absorption spectrum of ice from transmission of solar radiation into snow, Appl. Optics, 45, 5320-5334, doi:10.1364/ao.45.005320, 2006.

Xu, Z., Yang, Y., Wang, G., Cao, W., Li, Z., and Sun, Z.: Optical properties of sea ice in Liaodong Bay, J. Geophys. Res., 117, C03007, doi:10.1029/2010JC006756, 2012. 